Figure 1. Treating physician's clinical suspicion for GCA before and after VUS among 431 patients without a history of GCA/aortitis

VUS positive for acute arteritis $(n=35)$

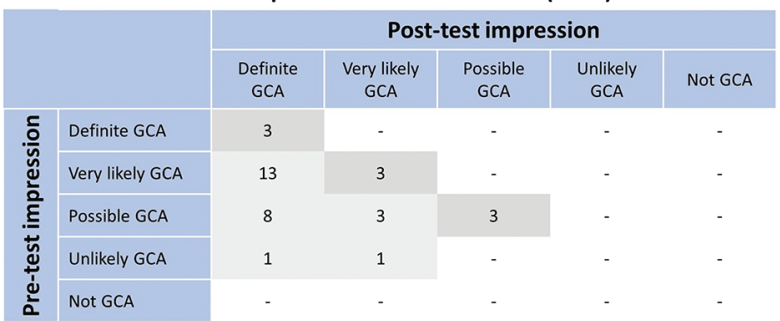

VUS negative for acute arteritis $(n=396)$

\begin{tabular}{|c|c|c|c|c|c|c|}
\hline & \multicolumn{5}{|c|}{ Post-test impression } \\
\hline & & $\begin{array}{l}\text { Definite } \\
\text { GCA }\end{array}$ & $\begin{array}{c}\text { Very likely } \\
\text { GCA }\end{array}$ & $\begin{array}{c}\text { Possible } \\
\text { GCA }\end{array}$ & $\begin{array}{l}\text { Unlikely } \\
\text { GCA }\end{array}$ & Not GCA \\
\hline \multirow{5}{*}{ 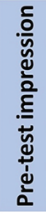 } & Definite GCA & 1 & - & - & 1 & - \\
\hline & Very likely GCA & 4 & 9 & 7 & 9 & 5 \\
\hline & Possible GCA & 3 & 2 & 35 & 41 & 141 \\
\hline & Unlikely GCA & - & - & 2 & 20 & 99 \\
\hline & Not GCA & - & 1 & - & 2 & 14 \\
\hline & Increased suspicion & \multicolumn{3}{|c|}{ No change } & \multicolumn{2}{|c|}{ Decreased suspicion } \\
\hline
\end{tabular}

Abstract THU0300 - Figure 1

Disclosure of Interests: None declared DOI: 10.1136/annrheumdis-2019-eular.1471

\section{THU0301 SPLENIC INVOLVEMENT IS NOT RARE IN ANCA- ASSOCIATED VASCULITIS HOWEVER SPLENIC INFARCT MIGHT ONLY BE ASSOCIATED WITH GRANULOMATOSIS WITH POLYANGIITIS}

Önay Gerçik ${ }^{1}$, Şebnem Karasu ${ }^{2}$, Dilek Solmaz ${ }^{1}$, Zeki Soypaçacı ${ }^{3}$,

Fulya Çakalağaoğlu ${ }^{4}$, Servet Akar ${ }^{1} .{ }^{1}$ Izmir Katip Celebi University Faculty of Medicine, Rheumatology, Izmir, Turkey, ${ }^{2}$ Izmir Katip Celebi University Faculty of Medicine, Radiology, Izmir, Turkey; ${ }^{3}$ Izmir Katip Celebi University Faculty of Medicine, Nephrology, Izmir, Turkey; ${ }^{4}$ Izmir Katip Celebi University Faculty of Medicine, Pathology, Izmir, Turkey

Background: Anti-neutrophil cytoplasmic antibody (ANCA) associated vasculitis (AAV) is a systemic necrotizing vasculitis of small and mediumsized arteries. Although, upper and lower respiratory tracts and kidneys are predominantly affected; other organs/systems can also be involved in the course of the disease and in some cases, it might be difficult to differentiate subgroups based on the clinical presentation. Splenic involvement has been rarely reported, mainly in patients with granulomatosis with polyangiitis (GPA), in fact, it was thought to be underestimated, as it is often asymptomatic.

Objectives: In this study, we aimed to investigate systematically the frequency of splenic infarct and related factors in our AAV patients. We also evaluated the role of splenic involvement in the differentiation of AAV subgroups.

Methods: Patients with a diagnosis of AAV in whom abdomen/thorax computed tomography (CT) was performed were included in the study. An experienced radiologist examined CT images for the presence of splenic involvement. The clinical and demographic data were retrospectively collected.

Results: In total 70 (30 [43\%] female and mean age $56.1 \pm 15.7$ years) AAV patients (38 [54\%] had granulomatosis with polyangiitis (GPA); 20 [29\%] microscopic polyangiitis; 11 [16\%] renal-limited disease and 1 [1\%] eosinophilic granulomatosis with polyangiitis) were included in the analysis. Splenic pathologies including splenomegaly, hypodense lesion/s, lobulation, and infarction were seen in $21(30 \%)$ patients with AAV. Splenic infarct was observed in seven (10\%) patients and all had GPA with renal involvement and PR3ANCA positive. Three of them had total splenic infarct or auto-splenectomy. None of these patients had a history of endocarditis, shock or malignancy before CT. Splenic infarction was found to be negatively correlated with age at diagnosis $(p=0.017$; rho $=-0.285)$, and positively associated with ENT (ear-nose-throat) $(p=0.002$; rho $=0,370)$ and eye involvements $(p=0.013$; rho $=0,324)$
Conclusion: Our results show that splenic pathologies might not be rare in AAV however, infarction can help to separate GPA from other AAVs. In young GPA patients, in particular, those with ENT and eye involvement, physicians should remember splenic infarction. Since almost half of our cases had severe infarction or autosplenectomy, clinicians might con sider immunization in GPA patients for vaccine-preventable infections.

\section{REFERENCES:}

[1] Fishman D, Isenberg DA. Splenic involvement in rheumatic diseases. Semin Arthritis Rheum. 1997;27(3):141-55

[2] Ghinoi A, Pipitone N, Cavazza A, Boiardi L, Salvarani C. Wegener granulomatosis with spleen infarction: case report and review of the literature. Semin Arthritis Rheum. 2008;37(5):328-33

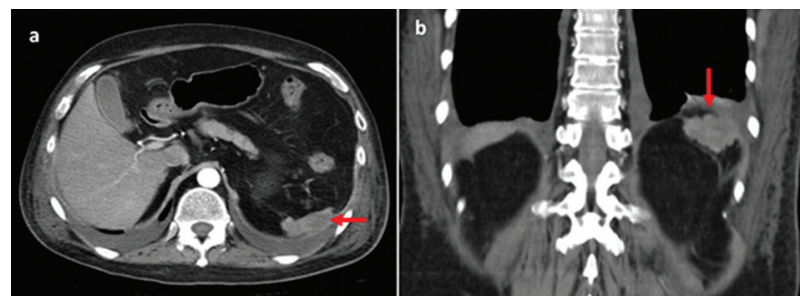

Abstract THU301 - Figure 1. Computed abdominal tomography scan of one the patients with splenic infarction; transverse (a) and coronal images (b) show an irregular contoured shrunken spleen (arrows).

Disclosure of Interests: Önay Gerçik: None declared, Şebnem Karasu: None declared, Dilek Solmaz: None declared, Zeki Soypaçacı: None declared, Fulya Çakalağaoğlu: None declared, Servet Akar Grant/research support from: MSD, Abbvie, Roche, UCB, Novartis, Pfizer, Amgen, Consultant for: MSD, Abbvie, Roche, UCB, Novartis, Pfizer, Amgen, Speakers bureau: Pfizer

DOI: 10.1136/annrheumdis-2019-eular.2745

\section{THU0302 OUTCOMES OF PREGNANCY IN BEHCET'S DISEASE}

Zemfira Alekberova ${ }^{1}$, Regina Goloeva ${ }^{2}$, Alexander Lila ${ }^{2}{ }^{1}$ V.A. Nasonova Research Institute of Rheumatology, Moscow, Russia., Moskow, Russian Federation; ${ }^{1}$ V.A. Nasonova Research Institute of Rheumatology, Moscow, Russia., Moskow, Russian Federation

Background: Behcet's disease (BD) is multisystemic disease of unknown cause. The relationship between BD and pregnancy is reported in limited number of studies.

Objectives: To evaluate outcomes of pregnancies in BD patients (pts). Methods: We retrospectively collected data of 22 women with BD diagnosis (according to ISGBD 1990 and ICBD 2014) and their 68 pregnancies. Pts' mean age was $30[26 ; 35]$ yrs, disease duration 7 [2;10] yrs. Ten $(45,5 \%)$ pts had severe $\mathrm{BD}$ according to Ch.Zouboulis classification (due to generalized uveitis, retinal vasculitis and parenchymatous CNS lesions), while other $10(45,5 \%)$ pts had mild disease with mainly dermal-mucous manifestations, and remaining two (9\%) pts had moderate disease. These patients did not receive cytotoxic therapy.

Results: Sixty-eight pregnancies in 22 pts resulted in 45 live birth (4 cesarean section in 2 pts). Four patients had 11 medical abortions on request before 12 weeks of gestation, one patient - due to medical reasons (rubella on the $7^{\text {th }}$ week of gestation). Seven $(32 \%)$ out of 22 pts had adverse pregnancy outcomes. Five (23\%) pts had 8 intrauterine deaths: one patient -3 intrauterine deaths (4-10 weeks), two pts - 2 (10-12 weeks) and one -1 intrauterine deaths (10 weeks). Two (9\%) pts had 3 miscarriages $5-10$ weeks. Antiphospholipid syndrome was never detected in pts from this cohort.

BD Severity and pathology of pregnancy

\begin{tabular}{lcc}
\hline BD Severity & $\mathrm{N}=22(\%)$ & Intrauterine deaths/Miscarriage \\
\hline Mild & $10(45,5)$ & $3 / 2$ \\
Moderate & $2(9)$ & $5 / 0$ \\
Severe & $10(45,5)$ & $0 / 1$ \\
\hline
\end{tabular}

Out of 45 babies children born by BD patients only two had relapsing aphthous stomatitis and one - congenital glaucoma ("Neurobehcet" inherited from mother).

Conclusion: BD pts demonstrated high rates of adverse pregnancy outcomes. Unfavorable outcomes of pregnancy were documented in pts regardless (with all grades of) BD severity. 


\section{REFERENCE:}

[1] Zouboulis C., Vaiopoulos G., Macromichelakis N. et al. Onset signs, clinical course, prognosis, treatment and outcome of adult patients with Adamantiades - Behcet's disease in Greece. Clin.Exp.Rheum.2003, 21, (suppl.30) S19-S26.

Disclosure of Interests: None declared

DOI: 10.1136/annrheumdis-2019-eular.6657

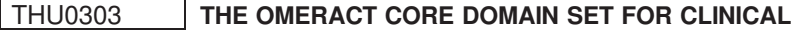 TRIALS IN BEHÇET'S SYNDROME}

Gulen Hatemi ${ }^{1}$, Alexa Meara ${ }^{2}$, Yesim Ozguler ${ }^{1}$, Haner Direskeneli ${ }^{3}$, Alfred Mahr ${ }^{4}$, Beverley Shea ${ }^{5}$, Esen $\mathrm{Cam}^{6}$, Ahmet Gül ${ }^{7}$, Yusuf Yazici ${ }^{8}$, Peter Tugwell ${ }^{5}$ Hasan Yazici ${ }^{9}$, Peter Merkel ${ }^{10}{ }^{1}{ }^{1}$ Istanbul University-Cerrahpasa, Istanbul, Turkey; ${ }^{2}$ Ohio State University Wexner Medical Center, Ohio, United States of America; ${ }^{3}$ Marmara Üniversity, School of Medicine, Istanbul, Turkey; ${ }^{4}$ Hospital Saint-Louis, Paris, France, ${ }^{5}$ University of Ottawa, Ontario, Canada; ${ }^{6}$ Marmara University, Istanbul, Turkey, ${ }^{7}$ Istanbul University Istanbul Faculty of Medicine, Istanbul, Turkey; ${ }^{8}$ New York University School of Medicine, New York. United States of America; ${ }^{9}$ Istanbul University-Cerrahpasa, Istanbul, Turkey; ${ }^{10}$ University of Pennsylvania, Philadelphia, United States of America

Background: There is an unmet need for reliable, validated, and widelyaccepted outcome measures for clinical trials in Behçet's syndrome (BS). Objectives: The Outcome Measures in Rheumatology Clinical Trials (OMERACT) Behçet's Syndrome Working Group has worked to advance the creation of a data-driven Core Domain Set for use in all clinical trials.

Methods: The Core Domain Set was developed through a comprehensive, iterative, multi-stage, multi-year project that followed the methodologically rigorous processes and standards set forth by OMERACT: i) a systematic review; ii) a survey among experts in BS; iii) an outcome measures interest group meeting during the International Conference on Behçet's Disease; iv) qualitative patient interviews; v) a three-round modified Delph exercise involving both patients with BS and a multidisciplinary set of physicians expert in BS, focused on obtaining consensus on the domains of illness necessary in the study of BS; and vi) utilization of the data, insight, and feedback generated by the outlined processes to develop a final Core Domain Set. The final Core Set was presented and put up for a vote of endorsement at the 2018 OMERACT meeting.

Results: All steps in the processes outlined were completed. The systematic review clearly demonstrated the substantial variability in the domains studied in clinical trials of BS and a lack availability of validated outcome measures in BS. The survey of physicians, the in-person meeting of experts, and the qualitative research with patients all helped generate an extensive list of candidate domains and sub-domains to consider for use in clinical trials. It also become clear that there was a need and strong interest in delineating domains across the several major organ systems involved in this disease and in recognizing that clinical trials in BS often focus on specific manifestations and not the disease in its entirety. The Delphi involved 74 physicians expert in BS from 21 countries and from a wide range of specialties, and 64 patients from 10 countries. The Delphi utilized both ratings and rankings to prioritize the 56 domains and subdomains originally under consideration.

The final proposed Core Set included 5 sub-domains mandatory for study in all trials in BS, with additional sub-domains mandatory for study of specific organ-systems when that system is the focus of a trial: mucocutaneous (2 additional sub-domains), ocular (4), central nervous system (3), musculoskeletal (2), vascular (4), and gastrointestinal (2). The final Core Set was strongly endorsed at the 2018 OMERACT meeting. Conclusion: Multiple disease-related domains in BS have been identified by physicians and patients as important to address in clinical trials, leading to the development and endorsement of a final Core Set of Domains for use in clinical trials in BS. The Core Set provides the foundation through which the international research community, including clinical investigators, patients, the biopharmaceutical industry, and government regulatory bodies can harmonize the study of this complex disease, compare findings across studies, and advance development of effective agents.

Disclosure of Interests: : Gulen Hatemi Consultant for: Abbvie, Amgen, BMS, Janssen, MSD, Pfizer, UCB, Speakers bureau: Abbvie, Amgen, BMS, Jansen, MSD, Pfizer, UCB, Alexa Meara: None declared, Yesim Ozguler: None declared, Haner Direskeneli: None declared, Alfred Mahr: None declared, Beverley Shea: None declared, Esen Cam: None declared, Ahmet Gül: None declared, Yusuf Yazici Shareholder of: Samumed, LLC, Consultant for: Celgene Corporation, BMS, Genentech,
Sanofi, Employee of: Samumed, LLC, Peter Tugwell: None declared, Hasan Yazici: None declared, Peter Merkel: None declared DOI: 10.1136/annrheumdis-2019-eular.7080

\section{THU0304 PREVALENCE AND MANAGEMENT OF CARDIOVASCULAR RISK FACTORS IN ANCA- ASSOCIATED VASCULITIS: A CROSS-SECTIONAL STUDY IN THE NETHERLANDS AND CANADA}

Eline Houben ${ }^{1}$, Arielle Mendel ${ }^{2}$, Joost van der Heijden ${ }^{3}$, Suat Simsek ${ }^{1}$, Willem Bax ${ }^{1}$, Simon Carette ${ }^{2}$, Alexandre Voskuyl ${ }^{4}$, Christian Pagnoux ${ }^{2}$, Erik Penne $1 .{ }^{1}$ Northwest Clinics, Internal Medicine, Alkmaar, Netherlands; ${ }^{2}$ Mount Sinai Hospital, Vasculitis clinic, Department of Medicine, Toronto, Canada;

${ }^{3}$ Amsterdam UMC, Nephrology, Amsterdam, Netherlands; ${ }^{4}$ Amsterdam UMC, Rheumatology, Amsterdam, Netherlands

Background: Patients with ANCA-associated vasculitis (AAV) are at increased risk of cardiovascular (CV) disease.(1)

Objectives: The aim of the present study was to determine the prevalence of $\mathrm{CV}$ risk factors in patients with $\mathrm{AAV}$ and to evaluate the management of $\mathrm{CV}$ risk factors according to current guidelines.

Methods: A cross-sectional study was performed in patients with AAV in the Netherlands and Canada. Information on traditional CV risk factors, as well as markers of inflammation and kidney function, were collected. Their prevalence and treatment were studied and compared with recommendations in current guidelines.

Results: A total of 144 consecutive patients with AAV were included (71 from the Netherlands; 73 from Canada). Mean age was $62 \pm 15$ years, and $56 \%$ were male. The mean disease duration was $7.0 \pm 6.6$ years $69 \%$ had granulomatosis with polyangiitis, $17 \%$ microscopic polyangiitis and $14 \%$ eosinophilic granulomatosis with polyangiitis. Mean body mass index was $28+6 \mathrm{~kg} / \mathrm{m}^{2}$ and 65 patients $(45 \%)$ had an estimated glomerular filtration rate $<60 \mathrm{ml} / \mathrm{min}$. The mean $\mathrm{C}$-reactive protein was $6.5 \pm$ $12.3 \mathrm{mg} / \mathrm{l}$. Dyslipidemia was present in $69 \%$ and hypertension in $72 \%$. In $36 \%$ and $25 \%$ of the included patients, blood pressure and dyslipidemia, respectively, were not managed in accordance with national guidelines. Conclusion: Patients with AAV have a high prevalence of traditional CV risk factors. Whether past or persistent inflammation and chronic kidney disease further increases the CV risk remains to be studied. Strict adherence to $\mathrm{CV}$ risk management guidelines should be encouraged.

\section{REFERENCE:}

[1] Houben E, Penne EL, Voskuyl AE, van der Heijden JW, Otten RHJ, Boers $\mathrm{M}$, et al. Cardiovascular events in anti-neutrophil cytoplasmic antibodyassociated vasculitis: a meta-analysis of observational studies. Rheumatology (Oxford) 2018; 57: 555-62.

Disclosure of Interests: None declared DOI: 10.1136/annrheumdis-2019-eular.704

\section{THU0305 ABSTRACT WITHDRAWN}

\section{THU0306 NEUTROPHIL ADHESION MOLECULES AND INFLAMMATORY CYTOKINES AS BIOMARKERS FOR MONITORING DISEASE PROGRESSION IN GIANT CELL ARTERITIS}

Tadeja Kuret $^{1,2}$, Katja Lakota $^{1,3}$, Gerhard Thallinger ${ }^{4,5}$, Polona Zigon ${ }^{1}$, Sasa Cucnik ${ }^{1,2}$, Matija Tomsic ${ }^{1,6}$, Snežna Sodin-Šemr ${ }^{1,3}$, Alojzija Hocevar ${ }^{1}$. ${ }^{1}$ University Medical Centre Ljubljana, Department of Rheumatology, Ljubljana, Slovenia; ${ }^{2}$ University of Ljubljana, Faculty of Pharmacy, Ljubljana, Slovenia; ${ }^{3}$ University of Primorska, FAMNIT, Koper, Slovenia; ${ }^{4}$ Graz University of Technology, Institute of Computational Biotechnology, Graz, Austria; ${ }^{5}$ BioTechMed Graz, OMICS Center Graz, Graz, Austria; ${ }^{6}$ University of Ljubljana, Faculty of Medicine, Ljubljana, Slovenia

Background: Monitoring giant cell arteritis (GCA) activity with appropriate biomarkers is important, as current evaluation, based mainly on clinical symptoms/signs and traditional markers of inflammation, is not always suf ficient and reliable.

Objectives: Our goal was to identify cellular and molecular biomarkers that could help clinicians to closely monitor GCA progression and/or treatment response.

Methods: Peripheral blood was obtained from 27 GCA patients at time of diagnosis (before glucocorticoid (GC) treatment), and subsequently at 